\title{
Preauricular Sinus: A Tale of Forgetful Rediscovery
}

Boyko Matev ${ }^{1}$, Emran Lyutfi ${ }^{1}$, George S. Stoyanov ${ }^{2}$, Nikolay R. Sapundzhiev ${ }^{3}$

1. Medicine, Medical University of Varna, Varna, BGR 2. General and Clinical Pathology/Forensic Medicine and Deontology, Medical University of Varna, Varna, BGR 3. Otolaryngology, Medical University of Varna, Varna, BGR

Corresponding author: George S. Stoyanov, georgi.geesh@gmail.com

\begin{abstract}
The preauricular sinus (PAuS) is a congenital foramen, opening or invagination, usually located on the crus of the auricular helix and is considered a congenital malformation and component of multiple syndromes. The structure can be present unilaterally or bilaterally, with the possibility of more than one fistula present on one ear, predominantly on the auricular tags. As a well-defined and established clinical entry, PAuS has a very strictly laid-out history. However, different works of art give us a glimpse into the structure before its first true clinical description, showing that the PAuS was known to man long before it was first clinically described, such as those of Hieronymous Bosch, with the first medical descriptions being attributed to Heusinger and Virchow. In modern times, the condition is considered both an individual malformation and a component of several genetic syndromes.
\end{abstract}

Categories: Genetics, Medical Education, Otolaryngology

Keywords: preauricular sinus, medical history, genetic syndromes, medicine in art

\section{Introduction And Background}

The preauricular sinus (PAuS) is a congenital malformation characterized by a dent, dimple, or a foramen, usually located on the crus of the auricular helix [1-2]. Rarely structures with the same characteristics and clinical course can be found on the pinna, tragus, or even in the postauricular area contradictory to the established name in modern times [1-3].

The structure can be present unilaterally or bilaterally, with the possibility of more than one fistula present on one ear, predominantly on the auricular tags [3-6]. The structure presents as a simple epithelial invagination into the auricular stroma and can often become inflamed, leading to discharge from the superficial opening and discomfort [1,7]. This itself can lead to serious complications, such as facial paralysis, due to its location near the facial nerve $[1,7,8]$. Clinical history in such cases is important to distinguish between a fistulized abscess and an inflamed PAuS. Furthermore, chronic inflammation is a risk factor for cancerogenesis, and thus a squamous cell carcinoma ex PAuS (carcinoma from a PAuS) may

Received 06/08/2020 Review began 06/20/2020 Review ended 06/23/2020 Published 06/28/2020

() Copyright 2020 Matev et al. This is an open access article distributed under the terms of the Creative Commons Attribution License CC-BY 4.0., which permits unrestricted use, distribution, and reproduction in any medium, provided the original author and source are credited. develop later in life [9-11]. This is the reason why the structure evokes the interest of many otolaryngologists, specialists, and pediatricians.

As a well-defined and established clinical entry, PAuS has multiple contributors in the medical field that helped define it and its significance. However, different works of art give us a glimpse into the structure before its first true clinical description, showing that the PAuS was known to man long before it was first clinically described.

\section{Review}

\section{Artistic representation}

Hieronymus Bosh (c. 1450-1516) was a Dutch artist whose most famous painting is "The Garden of Earthly Delights". The painting illustrates exterior and interior panels [11]. The exterior panel resembles the creation of the world, whereas the interior consists of three panels that represent, respectively, The Garden of Eden (left panel), The Human World (middle panel), and The Judgment Day or Hell (right panel). A small segment of the right panel illustrates a pair of ears on which a structure resembling a PAuS is seen (Figure 1) [12]. 


\section{Cureus}

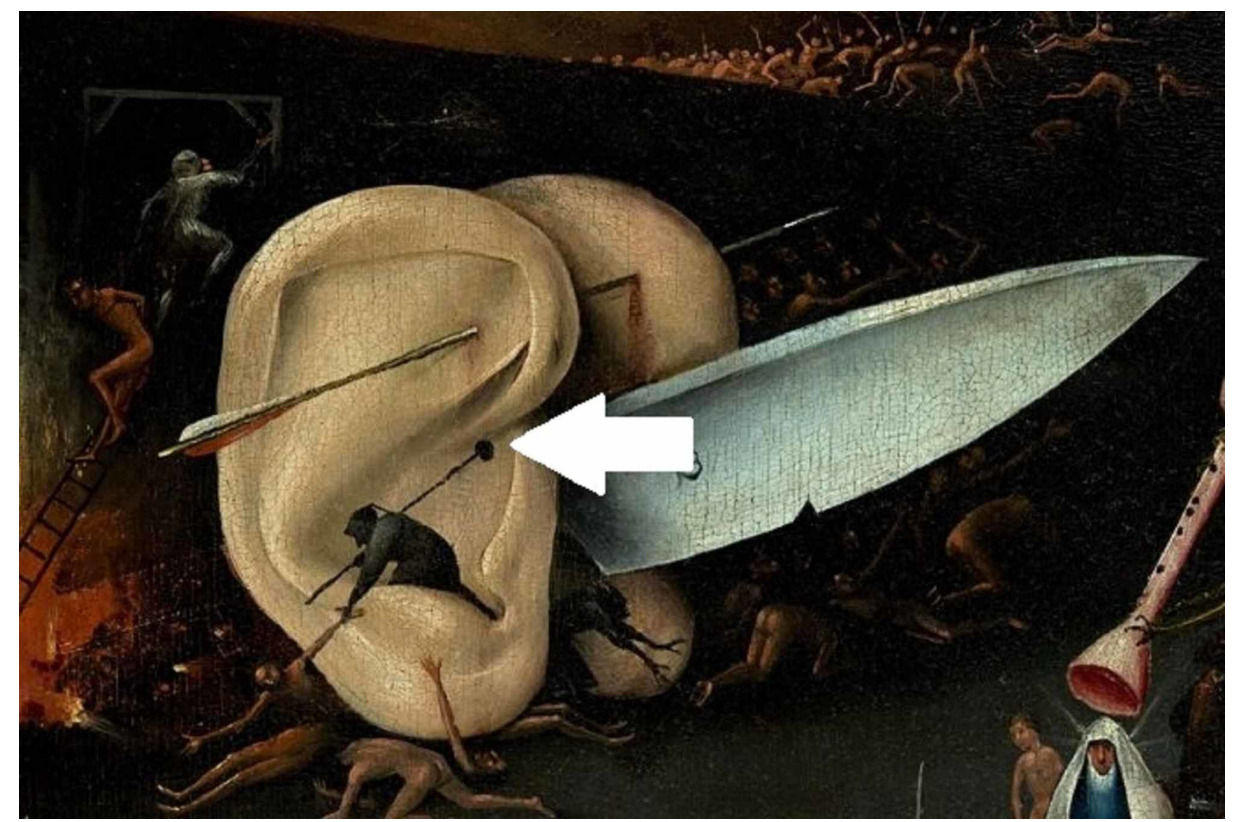

FIGURE 1: Hieronymous Bosch, Garden of Earthly Delights, a magnified section of the right panel of the interior section (Hell). The grotesque ear has a structure reminiscing of a PauS (arrow).

PAuS, preauricular sinus

\section{First medical descriptions}

The PAuS was first described in 1864 by C. F. Heusinger when describing the findings in a patient characteristic of the brachio-oto-renal (BOR) syndrome [13]. He detailed his finding and also referred to several already described phenomena that seemed detached from each other, such as the preliminary work by Dzondi, who described and defined congenital tracheal fistulas [13]. It is important to note that the auricula entity described by Heusinger, although morphologically identical, is its separate entity from the cervical and other brachial fistulas described before his observations [13,14].

Following Heusinger's description, Rudolph Virchow (1821-1902) also described the structure in 1864, although simply stating in his article "I also know a patient like that" [14]. Virchow, however, was the first to postulate that the PAuS is a result of a defect in the embryological fusion of the pharyngeal arches, a statement that was widely contradicted at the time (Figure 2). 


\section{Cureus}

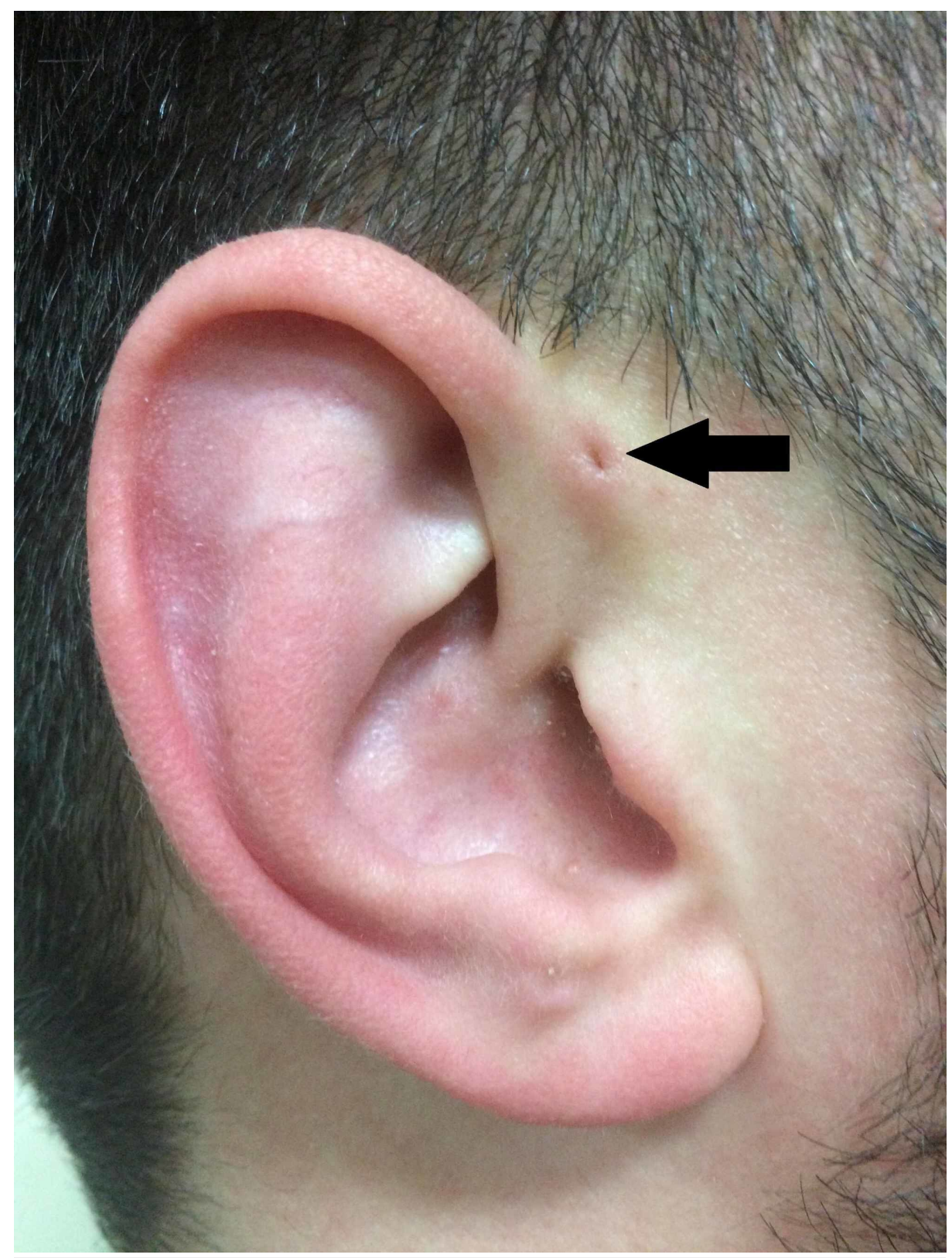

FIGURE 2: Classical representation of PAuS (arrow).

PAuS, preauricular sinus

Sir James Paget also published on the subject in 1878, describing patients with such fistulae present not only on their ears but also on their neck [15]. Based on the description of his patients, he coined the term otobranchial fistula [15] (Figure 3). Sir James Paget widely adapted the viewpoints of Virchow's theory of the origin of PAuS. 


\section{Cureus}

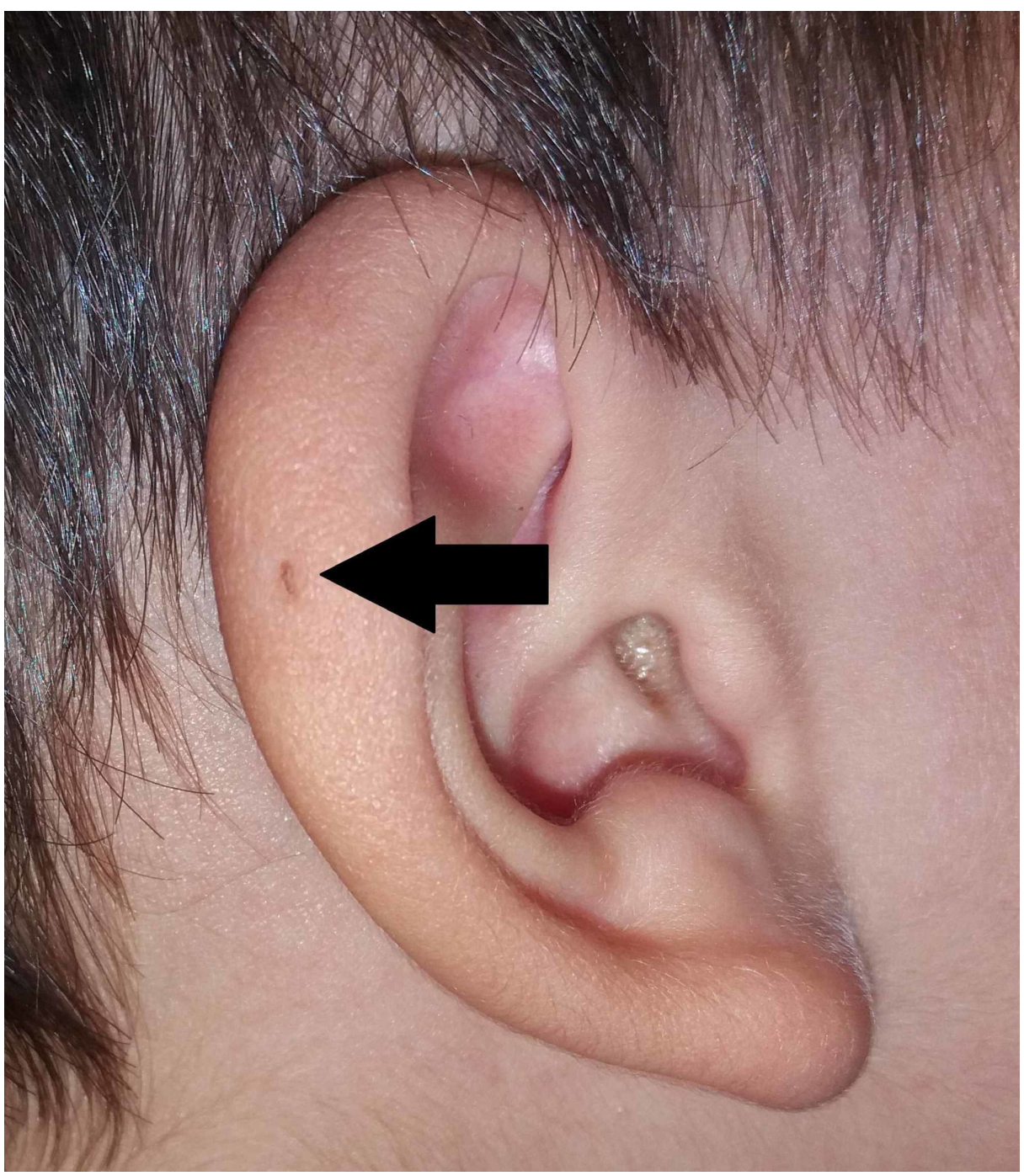

FIGURE 3: Variant of PAuS on the auricular helix (arrow).

PAuS, preauricular sinus

During the first part of the 20th century, the PAuS became known as "natural earring holes" and "fistula auris congenita", with several authors publishing on the subject, including its pattern of inheritance $[3,15,16]$. The phenomena and its transgenerational inheritance allowed for an extensive set of studies and theories on its cause, widely converging on Virchow's original statements [17-23].

One of the most important contributions from that time period was in 1955 by Fourman and Fourman, who researched the inheritance of PAuS, constructing a genealogical tree, focusing on the inheritance of the structure [24]. They concluded that half of the siblings of the affected family have the structure and thus postulated that the sinus is inherited as a dominant trait, but with "incomplete penetrance" due to it skipping in generations or individuals [24].

Despite that initial interest, however, little to no articles were published after the late 1940s, until a small resurgence in later years, where the structure reappears under a new name - PAuS. Since then, research on the structure has seldom been carried out, and the mechanisms of its transgenerational inheritance remain widely forgotten in the literature of the 1930s and 1940s.

\section{PAuS-associated syndromes}

\section{Melnick-Fraser Syndrome}

The syndrome was first described in 1864 by Heusinger [13]. However, in 1975, Melnick et al. described a series of patients with it, and in 1980 Fraser et al. described another series of cases with the hallmarks of the syndrome in a specialized school for the deaf $[25,26]$. The condition is considered relatively rare, with 250 new cases of Melnick-Fraser being diagnosed in Japan in 2014 [27]. First believed to be a variant of BOR 
syndrome, later on, Melnick widened the syndrome into a group of nearly identical conditions dependent on the presence or absence of different hallmarks [28,29]. The term Melnick-Fraser syndrome was later coined to unify the characteristics of the separate syndromes and to completely separate it from Fraser syndrome, isolated urogenital malformations, and Frasier-Lynch syndrome, familial colorectal polyposis, with which BOR had quite often been confused as a term at that point in time. Thus, sadly Heusinger's contribution has been widely forgotten.

\section{Beckwith-Wiedemann Syndrome}

The condition was originally described in 1963 by American pathologist John Beckwith as a combination of exomphalos, macroglossia, and gigantism, therefore referred to as exomphalos-macroglossia-gigantism (EMG) syndrome (Poster: Beckwith, JB: Extreme Cytomegaly of the adrenal Fetal Cortex, Hyperplasia of the Kidneys and Pancreas, and Leydig-Cell Hyperplasia : Another Syndrome?. Annual Meeting of Western Society for Pediatric Research, Los Angeles, CA, November 11, 1963). In 1964, however, independently of John Beckwith, the German pediatrician Hans-Rudolph Wiedemann also described several patients with the same hallmarks of the disease but also included symptoms such as adrenal hyperplasia [30]. Over time, the syndrome was dubbed Beckwith-Wiedemann syndrome, and the diagnostic criteria were expanded to include PAuS, hyperplastic kidneys, microcephaly, neonatal hypoglycemia, and hepatoblastoma developing later in life [31,32]. Mutations in 11p15 involving genes such as insulin-like growth factor 2 (IGF-2), cyclindependent kinase inhibitor 1C (CDKN1C), H19, and potassium voltage-gated channel subfamily Q member 1 overlapping transcript 1 (KCNQ1OT1) have been established in such patients [32]. The mechanism of inheritance is still undefined as in several patients with this condition, the exact transgenerational inheritance could not be determined, deeming it as a sporadic recessive defect. Beckwith-Wiedemann syndrome and its hallmarks are especially important to be distinguished in patients conceived with in vitro fertilization as the incidence in that population is much higher [33-35]. Beckwith-Wiedemann is considered a rare condition with an incidence of 1 per 13,700 children born, accounting for a total of about 300 children born with Beckwith-Wiedemann in the United States of America annually [36].

\section{Lachiewicz-Sibley Syndrome}

First described in 1985 by Lachiewicz et al., this is one of the rarest syndromes ever described [37]. The syndrome is very similar to Melnick-Fraser, though only PAuS and hypoplastic kidneys with early-onset proteinuria were found in the descendants of British and Irish immigrants settling in Ohio in the 1800s and later Nebraska. At the time of the original study, from 130 living relatives, 12 members had PAuS and hypoplastic kidneys, 10 had only hypoplastic kidneys, and 3 had only PAuS [37]. Although the exact locus of mutation remains unknown, the condition is inherited in an autosomal dominant fashion.

\section{Twenty-first century}

Today although still relatively under-researched, the PAuS is a common clinical entity with well-defined clinical strategies for treatment. Some studies have identified a genetic association between PAuS and the 8q11.1-13.1 locus; however, the results have not been reproduced widely [1,5,7,38]. Other than this individual study, no other studies have focused on the genetic reason for PauS nor have associated it with the aforementioned genetic syndromes, with genealogic studies are few and far in-between $[16,24,39]$.

The clinical course has been well described, and treatment strategies including predominantly surgical excision have been well established in modern otorhinolaryngology and head and neck surgery $[5,7,8,40]$. Nowadays, patients with PAuS, not associated with a genetic syndrome, undergo a safe intervention process with few described complications, whereas patients with genetic syndromes undergo the same curative modalities, and the excision of the PauS does not affect their overall clinical course $[7,40-42]$.

\section{Conclusions}

The PAuS, as it was first described, is often a component of several eponymous inherited syndromes such as Melnik-Fraser (BOR syndrome), Beckwith-Wiedemann, and Lachiewicz-Sibley, which also include a variety of constant kidney and other distant variable malformities such as cysts, fistulae, facial and neural defects, and others. These syndromes relatively rarely underline the importance of Virchow's original statement that the condition is caused by malfusion of pharyngeal arches, a process taking place parallel to some stages of kidney development. However, there is no evidence in the scientific literature inferring that the presence of PAuS always concludes to the presence of any of the aforementioned syndromes. Although the exact model of inheritance of the PauS, according to modern understandings and its genetic and molecular hallmarks, are yet to be fully determined and described, some authors still consider it as an irregular dominant mutation with reduced penetrance.

\section{Additional Information}

Disclosures

Conflicts of interest: In compliance with the ICMJE uniform disclosure form, all authors declare the following: Payment/services info: All authors have declared that no financial support was received from 
any organization for the submitted work. Financial relationships: All authors have declared that they have no financial relationships at present or within the previous three years with any organizations that might have an interest in the submitted work. Other relationships: All authors have declared that there are no other relationships or activities that could appear to have influenced the submitted work.

\section{References}

1. Scheinfeld NS, Silverberg NB, Weinberg JM, Nozad V: The preauricular sinus: a review of its clinical presentation, treatment, and associations. Pediatr Dermatol. 2004, 21:191-6. 10.1111/j.07368046.2004.21301.x

2. Kim HJ, Lee JH, Cho HS, Moon IS: A case of bilateral postauricular sinuses . Korean J Audiol. 2012, 16:99101. 10.7874/kja.2012.16.2.99

3. Kim JR, Kim DH, Kong SK, Gu PM, Hong TU, Kim BJ, Heo KW: Congenital periauricular fistulas: Possible variants of the preauricular sinus. Int J Pediatr Otorhinolaryngol. 2014, 78:1843-8. 10.1016/j.ijporl.2014.08.005

4. Waheed El-Anwar M, Shaker Elaassar A: Supra-auricular versus sinusectomy approaches for preauricular sinuses. Int Arch Otorhinolaryngol. 2016, 20:390-3. 10.1055/s-0036-1583305

5. Tan T, Constantinides H, Mitchell TE: The preauricular sinus: a review of its aetiology, clinical presentation and management. Int J Pediatr Otorhinolaryngol. 2005, 69:1469-74. 10.1016/j.ijporl.2005.07.008

6. Choi SJ, Choung Y-H, Park K, Bae J, Park HY: The variant type of preauricular sinus: postauricular sinus . Laryngoscope. 2007, 117:1798-802. 10.1097/MLG.0b013e3180caa1ca

7. Choo OS, Kim T, Jang JH, Choung YH: The clinical efficacy of early intervention for infected preauricular sinus. Int J Pediatr Otorhinolaryngol. 2017, 95:45-50. 10.1016/j.ijporl.2017.01.037

8. Rataiczak H, Lavin J, Levy M, Bedwell J, Preciado D, Reilly BK: Association of recurrence of infected congenital preauricular cysts following incision and drainage vs fine-needle aspiration or antibiotic treatment. JAMA Otolaryngol Neck Surg. 2017, 143:131-134. 10.1001/jamaoto.2016.2988

9. Pastore PN, Erich JB: Congenital preauricular cysts and fistulas . Arch Otolaryngol - Head Neck Surg. 1942, 36:120-5. 10.1001/archotol.1942.03760010130011

10. Martín-Granizo R, Pérez-Herrero MC, Sánchez-Cuéllar A: Methylene blue staining and probing for fistula resection: application in a case of bilateral congenital preauricular fistulas. Int J Oral Maxillofac Surg. 2002, 31:439-41. 10.1054/ijom.2001.0062

11. Stoyanov GS, Kitanova M, Dzhenkov DL, Ghenev P, Sapundzhiev N: Demographics of head and neck cancer patients: a single institution experience. Cureus. 2017, 9:e1418. 10.7759/cureus.1418

12. Mudry A: Hieronymus Bosch’s stamps: realistic, satyrical, grotesque and otorhinolaryngological. Hist Otorhinolaryngol. 2017, 1:189-213.

13. Heusinger CF: Hals-Kiemen-Fisteln von noch nicht beobachteter form. Arch Pathol Anat Physiol Klin Med. 1864, 29:358-80.

14. Virchow R: Ueber missbildungen am ohr und im bereiche des ersten kiemenbogens . Arch Pathol Anat Physiol Klin Med. 1864, 30:221-34. 10.1007/BF02280896

15. Paget J: Cases of branchial fistulæ in the external ears . Med Chir Trans. 1878, 61:41-50. 10.1177/095952877806100105

16. Donald GF: Fistula auris congenita. Australas J Dermatol. 1952, 1:253-5. 10.1111/j.14400960.1952.tb01437.x

17. Edmonds HW, Keeler CE: Natural “ear-ring” holes. J Hered. 1940, 31:507-10. 10.1093/oxfordjournals.jhered.a104828

18. Kindred JE: Inheritance of a pit in the skin of the left ear . J Hered. 1921, 12:366-7. 10.1093/oxfordjournals.jhered.a102125

19. McDonough ES: On the inheritance of ear pit. J Hered. 1941, 32:169-70. 10.1093/oxfordjournals.jhered.a105028

20. Whitney DD: Three generations of ear pits. J Hered. 1939, 30:323-4. 10.1093/oxfordjournals.jhered.a104753

21. Connon FE: The inheritance of ear pits in six generations of a family . J Hered. 1941, 32:413-6. 10.1093/oxfordjournals.jhered.a104980

22. Wood-Jones F, I-Chuan W: The development of the external ear. J Anat. 1934, 68:525-33.

23. Quelprud T: Ear pit and its inheritance. J Hered. 1940, 31:379-84. 10.1093/oxfordjournals.jhered.a104934

24. Fourman P, Fourman J: Hereditary deafness in family with ear-pits (fistula auris congenita). Br Med J. 1955, 2:1354-6. 10.1136/bmj.2.4952.1354

25. Melnick M, Bixler D, Silk K, Yune H, Nance WE: Autosomal dominant branchiootorenal dysplasia. Birth Defects Orig Artic Ser. 1975, 11:121-8.

26. Fraser FC, Sproule JR, Halal F, Optiz JM: Frequency of the branchio-oto-renal (BOR) syndrome in children with profound hearing loss. Am J Med Genet. 1980, 7:341-9. 10.1002/ajmg.1320070316

27. Morisada N, Nozu K, Iijima K: Branchio-oto-renal syndrome: comprehensive review based on nationwide surveillance in Japan. Pediatr Int. 2014, 56:309-14. 10.1111/ped.12357

28. Melnick M, Hodes ME, Nance WE, Yune H, Sweeney A: Branchio-oto-renal dysplasia and branchio-oto dysplasia: two distinct autosomal dominant disorders. Clin Genet. 1978, 13:425-42. 10.1111/j.13990004.1978.tb04142.x

29. Melnick M: Hereditary hearing loss and ear dysplasia-renal adysplasia syndromes: syndrome delineation and possible pathogenesis. Birth Defects Orig Artic Ser. 1980, 16:59-72.

30. Wiedemann HR: [Familial malformation complex with umbilical hernia and macroglossia - a new syndrome] J Genet Hum. 1964, 13:223-32.

31. Elliott M, Bayly R, Cole T, Temple IK, Maher ER: Clinical features and natural history of BeckwithWiedemann syndrome: presentation of 74 new cases. Clin Genet. 2008, 46:168-74. 10.1111/j.13990004.1994.tb04219.x

32. Pappas JG: The clinical course of an overgrowth syndrome, from diagnosis in infancy through adulthood: the case of Beckwith-Wiedemann syndrome. Curr Probl Pediatr Adolesc Health Care. 2015, 45:112-7. 


\section{Cureus}

10.1016/j.cppeds.2015.03.001

33. Chang AS, Moley KH, Wangler M, Feinberg AP, DeBaun MR: Association between Beckwith-Wiedemann syndrome and assisted reproductive technology: a case series of 19 patients. Fertil Steril. 2005, 83:349-54. 10.1016/j.fertnstert.2004.07.964

34. Maher ER, Brueton LA, Bowdin SC, et al.: Beckwith-Wiedemann syndrome and assisted reproduction technology (ART). J Med Genet. 2003, 40:62-4. 10.1136/jmg.40.1.62

35. Gicquel C, Gaston V, Mandelbaum J, Siffroi J-P, Flahault A, Le Bouc Y: In vitro fertilization may increase the risk of Beckwith-Wiedemann syndrome related to the abnormal imprinting of the KCN1OT gene. Am J Hum Genet. 2003, 72:1338-41.

36. Thorburn MJ, Wright ES, Miller CG, Smith-Read EH: Exomphalos-macroglossia-gigantism syndrome in Jamaican infants. Am J Dis Child. 1970, 119:316-21. 10.1001/archpedi.1970.02100050318006

37. Lachiewicz AM, Sibley R, Michael AF: Hereditary renal disease and preauricular pits: report of a kindred . J Pediatr. 1985, 106:948-50. 10.1016/S0022-3476(85)80248-1

38. Zou F, Peng Y, Wang X, et al.: A locus for congenital preauricular fistula maps to chromosome 8q11.1-q13.3 . J Hum Genet. 2003, 48:0155-8. 10.1007/s100380300024

39. An SY, Choi HG, Lee JS, Kim JH, Yoo SW, Park B: Analysis of incidence and genetic predisposition of preauricular sinus. Int J Pediatr Otorhinolaryngol. 2014, 78:2255-7. 10.1016/j.ijporl.2014.10.027

40. Gan EC, Anicete R, Tan HKK, Balakrishnan A: Preauricular sinuses in the pediatric population: techniques and recurrence rates. Int J Pediatr Otorhinolaryngol. 2013, 77:372-8. 10.1016/j.ijporl.2012.11.029

41. Stoyanov GS, Renjilian A, Matev B, et al.: Preauricular sinus: incidence and inheritance. Scri Sci Med. 2018, 50:24-9. 10.14748/ssm.v50i4.5650

42. Leung AKC, Robson WLM: Association of preauricular sinuses and renal anomalies . Urology. 1992, 40:25961. 10.1016/0090-4295(92)90487-H 